\title{
Psychiatric services in Algeria
}

\author{
Zoubir Benmebarek
}

EHS Psychiatrique El Madher Batna, Algeria, email zoubirbenmeb@gmail.com
The paper describes the current provision of psychiatric services in Algeria - in particular, in-patient and out-patient facilities, child psychiatry and human resources. Education, training, associations and research in the field of mental health are also briefly presented. The challenges that must dealt with to improve psychiatric care and to comply with international standards are listed, by way of conclusion.

Algeria is the largest country in Africa, with an area of $2382000 \mathrm{~km}^{2}$. The population is 37.9 million (Office National des Statistiques, 2013). The country is in the upper middle income group (United Nations, 2012). It is divided into 48 departments. Oil and gas are the main sources of national income. In 2012 Algeria's gross domestic product (GDP) amounted to US $\$ 210.2$ billion and its gross national income (GNI) per capita was US $\$ 5330$ (World Bank, 2013).

In Algeria, neuropsychiatric disorders are estimated to contribute $13.1 \%$ of the global burden of disease (World Health Organization, 2011). The mean age of the population is 26.6 years (World Health Organization, 2014) and life expectancy is 73 years (World Bank, 2013); $7.1 \%$ of the population is aged over 60 years.

The total expenditure on health is $5.2 \%$ of GDP (World Bank, 2013). Mental health expenditures by the Health Department represent $7.37 \%$ of the total health budget and mental hospital expenditures amount to $81.44 \%$ of the total mental health budget (World Health Organization, 2011).

\section{History of psychiatric services}

French colonial occupation (from 1830 to 1962) profoundly influenced the development of psychiatry in Algeria, both structurally and ideologically. In 1930 a large-scale plan was launched to create psychiatric settings out of nothing. Psychiatric departments were opened in general hospitals for acute patients (called first-line services) and the building was begun of large psychiatric hospitals for long-stay patients (called second-line services). They were run according to the 1838 French mental health law (Bégué, 1996). A hasty mass departure of French psychiatrists and nurses in 1962 left hospitals devoid of human resources to care for thousands of patients with mental illness and to handle the psychological consequences of a seven-year bloody war for independence. At that time the number of beds amounted to 6000 (Kacha, 2005, 2010).

\section{Organisation of mental health services}

The Ministry of Health is responsible for planning, budgeting and monitoring health services in a highly bureaucratic and centralised way. Hospitals are financed by both the Ministry of Health and the public national insurance company (Kacha, 2005).

The state provides psychiatric care free of charge. There are no private psychiatric hospitals in Algeria (Kacha, 2005, 2010). Most psychotropic drugs - even atypical antipsychotics - are available free of charge for people who have a chronic mental illness. Under an agreement on social welfare between the Ministry of National Solidarity and the public national insurance company, people with chronic mental disorders with insurance coverage receive a disability pension. No mental health services are available for the elderly, who are generally cared for by their families.

\section{In-patient services}

The main psychiatric hospitals date from the colonial era; few have been built since independence and the number of psychiatric beds has dropped from 6000 in 1962 to approximately 5000 beds nowadays, although the population has grown fourfold (Kacha, 2005, 2010; World Health Organization, 2011). It was only after the new millennium that the Health Department set out to build ten new psychiatric hospitals (Kacha, 2010). The country is divided into 15 psychiatric sectors (catchment areas) for voluntary hospitalisations, nine psychiatric sectors for involuntary admissions and three sectors for forensic hospitalisations (Kacha, 2005).

Of the 13 university hospitals, six have a department of psychiatry; there are 16 mental health specialist hospitals and 13 psychiatric wards in general hospitals (Zahir, 2012).

There are two hospital units for the treatment of substance misuse, one located in the centre of the country (Blida, 50 beds), the other in the west (Oran, 30 beds), and 23 out-patient clinics for addiction care. The Ministry has scheduled 15 hospitalisation units and 53 out-patient clinics for addiction care, to operate in the near future.

\section{Out-patient facilities}

Out-patient psychiatric care is predominantly provided at psychiatric dispensaries (called intermediate centres of mental health) by a psychiatrist and a nurse. They are located in cities and towns and cater for a geographical catchment area. The number of these centres is uneven across the country; large cities are better provided for than remote areas. Out-patient care is limited to 
providing consultation, and no other form of community care is available for adults; there are no community residential rehabilitation programmes.

\section{Child psychiatry}

Child and adolescent psychiatry departments are available in 14 psychiatric hospitals. All provide out-patient consultations and some of them day hospital care; there is no full hospitalisation for children. In 2006 a first group of child psychiatrists (about 25) fulfilled 9 months of training sponsored by the World Health Organization and in 2009 a second wave of 50 child psychiatrists took office in child services in remote regions of the country (Kacha, 2010). There is an increasing awareness of the importance of providing up-to-date care for children with mental disorders; a reform plan has been launched by the Department of Health and recently child and adolescent psychiatry has been raised to the status of independent specialty.

\section{Human resources}

At independence in 1962, three Algerian psychiatrists (who graduated in France and Switzerland) took over the management of public hospitals after the French physicians had left the country. Former Eastern European countries also provided psychiatrists, in agreement with the authorities, to overcome the shortage of medical staff. The first five psychiatrists graduated in Algeria in 1971. The situation is now far better, with approximately 615 psychiatrists ( 1.55 per 100000 population), of whom 215 work as private practitioners (Kacha, 2010). There are also 2128 nurses in psychiatry, of whom 427 are specialists, and 1368 psychologists (Zahir, 2012). However, there is a lack of trained social workers (World Health Organization, 2011).

\section{Medical training}

Eleven schools of medicine offer medical undergraduate education. It takes 7 years to get a medical degree. The 3-week externship in psychiatry is undertaken during the fifth year of medicine and includes lectures and clinical training. Medical psychology is taught during a 3 -week rotation in the sixth year.

To qualify as a psychiatrist, a graduate physician sits a local competitive examination; then the resident must undertake a 3-year full-time programme of education and training to graduate as an adult psychiatrist or child psychiatrist. A national examination takes place each year and includes a clinical case component and a theoretical component; no research thesis is required. Each year about 60 psychiatrists graduate nationally (Kacha, 2005). There is no national training in forensic or addiction psychiatry, or psychotherapy. Continuing medical education is not mandatory, although the Health Department regularly organises seminars on topics such as psychological trauma, addiction and autism. Training in cognitive-behavioural therapy or family therapy is possible through a programme of cooperation with European specialist associations.

\section{Mental health legislation and policy}

Mental health legislation and policy in Algeria are covered in some detail in the accompanying Mental Health Law Profile in this issue (pp. 12-15), and so are mentioned only briefly here.

The mental health legislation is based on the 1985 Mental Health Law, which primarily deals with various forms of hospitalisation. The Health Department launched a mental health programme in 2001 to improve the quality and efficiency of psychiatric care. There is an ongoing effort to reshape mental healthcare services, including reviewing legislation, decentralisation, integration of psychiatry into the primary care system and developing rehabilitation programmes.

\section{Psychiatric associations}

The flagship psychiatric association is the Algerian Psychiatric Society; it was established in 1969 but was not officially recognised until 1998. It holds an annual meeting and organises continuing medical education and international conferences in collaboration with French and Belgian psychiatric associations. It publishes a quarterly journal (Le Lien Psy). There are other national and local psychiatric associations, such as the Medicopsychological Association, the Association of Psychiatrists of Constantine, the Association of Private Psychiatrists and the Association of Psychiatrists of Oran.

The close link and cooperation between Algerian and French psychiatrists has given birth to the Franco-Algerian Psychiatric Association and the Franco-Maghrebi Psychiatric Association, both of which hold annual meetings alternately in France and in North Africa.

\section{Research}

Large epidemiological studies have not been carried out in Algeria, but many psychiatrists have performed local or regional studies on various topics, such as depression, suicide, psychosis and anxiety disorders. The data remain sparse. A general-population study in Algiers carried out in 2003 found the prevalence of anxiety disorders to be up to $43 \%$, of which $13 \%$ presented as posttraumatic stress disorder (Kacha, 2005). According to another study, the suicide rate in an eastern region of the country was 2 per 100000 per year and the rate of attempted suicide was 34.1 per 100000 per year (Bensmail, 1993).

\section{Conclusion}

There have been significant developments and undeniable improvements in mental health in Algeria in recent decades but more effort is needed to reform the mental health system, which still needs to be more efficient and more cost-effective. The main challenges of psychiatry today are:

- enacting a new mental health law

- reviewing the mental health programme

- increasing the number of medical and paramedical staff 
- creating social workers

- developing psychiatric departments in general hospitals

- integrating mental health service users and civil organisations in political decision-making.

And last but not least, emphasis should be put on the urgent need to develop community care and to establish rehabilitation programmes.

\section{References}

Bégué, J. M. (1996) French psychiatry in Algeria (1830-1962): from colonial to transcultural. History of Psychiatry, 7, 533-548.

Bensmail, B. (1993) Suicide et conduits suicidaires en milieu maghrébin. In La psychiatrie aujourd'hui (ed. B. Bensmail), p. 260. Office des Publications Universitaire.

Kacha, F. (2005) La psychiatrie en Algérie. L'Information Psychiatrique, 81, 145-148.
Kacha, F. (2010) La santé mentale en Algérie. Journée Parlementaire sur la Santé, 55-62. Available at http://www. majliselouma.dz/textes/autresdoc/JP\% 20sur \% 20la \% 20Sante2.pdf (accessed 26 January 2014).

Office National des Statistiques (2013) Data from http://www.ons. dz (accessed January 2014).

United Nations (2012) Statistical Annex. Available at http:// www.un.org/en/development/desa/policy/wesp/wesp_ current/2012country class.pdf (accessed July 2014).

World Bank (2013) Data from http://data.worldbank.org/country/ algeria (accessed 23 December 2014).

World Health Organization (2011) Mental Health Atlas. Available at http://www.who.int/mental_health/evidence/atlas/profiles/ dza_mh_profile.pdf (accessed December 2013).

World Health Organization (2014) Data from http://apps.who.int/ gho/data/node.country.country-DZA (accessed 21 December 2014).

Zahir, A. (2012) A l'issue du 1er congrès national de santé mentale, Ould Abbes annonce: dix huit projets de création de nouveaux établissements hospitaliers. Available at http://www.lactualite-dz. info (accessed 3 July 2014).
MENTAL HEALTHLAW PROFILE

\title{
Mental health legislation in Algeria
}

\author{
Zoubir Benmebarek
}

EHS Psychiatrique El Madher, Batna, Algeria, email zoubirbenmeb@gmail.com

\begin{abstract}
Mental health law in Algeria originates from the French colonial era. Although several pieces of legislation deal with mental disorders, their implementation remains unsatisfactory and does not meet the real needs of healthcare providers. Amendment of the current mental health law is required to enhance the delivery of care but also to protect those with a mental disorder from abuse.
\end{abstract}

Algeria is the largest country in Africa, with an area of $2382000 \mathrm{~km}^{2}$. The population is 37.9 million (Office National des Statistiques, 2013). The country is in the upper middle income group (United Nations, 2012). In Algeria, neuropsychiatric disorders are estimated to contribute $13.1 \%$ of the global burden of disease (World Health Organization, 2011). Further details of mental healthcare in the country are provided in the accompanying Country Profile on Algeria in this issue (pp. 10-12).

\section{Historical background}

Before the French army invaded Algeria in 1830, people with a mental illness, especially those presenting a risk to themselves or to others, were housed in the maristans (medical institutions) inherited from the Ottoman period. The care of patients with no behavioural disturbances was provided mainly by their families (Bégué, 1996).

In the early colonial era, patients were transferred to asylums in southern France. This persisted for more than a century despite the enactment in 1878 of a decree which extended the application of a French mental health law of 30 June 1838 to Algeria, the enforcement of which was hampered by a lack of hospitals.

Colonial psychiatry was founded by the 1912 Tunis congress of French alienists but the implementation of its recommendations began only in the 1930s (Bégué, 1996). At independence, in 1962, Algeria had about 6000 psychiatric beds and a network of hospitals and out-patient facilities (Kacha, 2005).

\section{After independence}

The French mental health law regulated psychiatric institutions till 1975 and the first Algerian mental health law was promulgated in 1976 (Decree 76-79 of 23 October 1976); it was based on the previous French law (Bakiri, 1993).

The second mental health law was introduced in 1985, in the form of the third chapter of the public health law (Law 85-05 of 16 February 1985). Modifications concerned the form rather than the content of the previous law (Bakiri, 1993). It is the legislation that applies today.

\section{Law 85-05}

Law 85-05 has four parts.

\section{Part 1}

This part covers the types of hospitalisation in psychiatric units. In some regards it is imprecise and even contradictory in its formulations. For 